\title{
Inhibition of cell expansion enhances cortical microtubule stability in the root apex of Arabidopsis thaliana
}

Veronica Giourieva ${ }^{1,2}$ and Emmanuel Panteris ${ }^{1 *}$

\begin{abstract}
Background: Cortical microtubules regulate cell expansion by determining cellulose microfibril orientation in the root apex of Arabidopsis thaliana. While the regulation of cell wall properties by cortical microtubules is well studied, the data on the influence of cell wall to cortical microtubule organization and stability remain scarce. Studies on cellulose biosynthesis mutants revealed that cortical microtubules depend on Cellulose Synthase A (CESA) function and/or cell expansion. Furthermore, it has been reported that cortical microtubules in cellulose-deficient mutants are hypersensitive to oryzalin. In this work, the persistence of cortical microtubules against anti-microtubule treatment was thoroughly studied in the roots of several cesa mutants, namely thanatos, mre1, any 1, prc1-1 and rsw1, and the Cellulose Synthase Interacting 1 protein (csi1) mutant pom2-4. In addition, various treatments with drugs affecting cell expansion were performed on wild-type roots. Whole mount tubulin immunolabeling was applied in the above roots and observations were performed by confocal microscopy.
\end{abstract}

Results: Cortical microtubules in all mutants showed statistically significant increased persistence against antimicrotubule drugs, compared to those of the wild-type. Furthermore, to examine if the enhanced stability of cortical microtubules was due to reduced cellulose biosynthesis or to suppression of cell expansion, treatments of wild-type roots with 2,6-dichlorobenzonitrile (DCB) and Congo red were performed. After these treatments, cortical microtubules appeared more resistant to oryzalin, than in the control.

Conclusions: According to these findings, it may be concluded that inhibition of cell expansion, irrespective of the cause, results in increased microtubule stability in A. thaliana root. In addition, cell expansion does not only rely on cortical microtubule orientation but also plays a regulatory role in microtubule dynamics, as well. Various hypotheses may explain the increased cortical microtubule stability under decreased cell expansion such as the role of cell wall sensors and the presence of less dynamic cortical microtubules.

Keywords: Arabidopsis thaliana, Cell expansion, Cell wall, Cellulose Synthase A, Colchicine, Cortical microtubules, Oryzalin

*Correspondence: epanter@bio.auth.gr

${ }^{1}$ Department of Botany, School of Biology, Aristotle University of Thessaloniki, 54124 Thessaloniki, Greece

Full list of author information is available at the end of the article

\section{Background}

Plant cell growth and morphogenesis are directed by cellulose microfibril orientation, which is controlled by the cortical microtubule array (among others see [1-3]). The regulatory role of cortical microtubules on cellulose microfibrils was initially postulated, and remains widely accepted, by the "alignment hypothesis" [4]. According to it, cellulose microfibrils run parallel to cortical 
microtubules, which guide the movement of Cellulose Synthase A (CESA) complexes (CSCs) [4, 5]. However, cortical microtubules reside just under the plasma membrane, while cellulose microfibrils are synthesized by transmembrane CSCs [6], consisting of CESA subunits. Specifically, the Arabidopsis thaliana genome encodes for 10 CESA isotypes [7, 8]. CESA1, CESA3 and CESA6 genes are essential in primary cell wall synthesis [9-11]. Three additional isoforms, the CESA2, CESA5 and CESA9 show sequence and functional redundancy with CESA6 subunit $[12,13]$, while CESA4, CESA7 and CESA8 are required for cellulose deposition in secondary walls $[7,8]$. Mutations in any of the CESA subunits, involved in primary wall synthesis, result in defective cellulose deposition, root radial swelling and reduced cell expansion $[9,10,14,15]$.

Even though the "alignment hypothesis" has been proposed decades ago, a mechanism explaining how cortical microtubules, located inside of the plasma membrane, control the orientation of cellulose microfibrils, outside of the protoplast, remained ambiguous. Several models have been proposed to answer the above-mentioned question [16-18]. The direct observation of CESA complexes sliding on the plasma membrane over the cortical microtubules [5] directly supported the model of Heath [16]. Additionally, it has been recently found that cortical microtubules are connected to CESA complexes via the Cellulose Synthase Interacting 1 (CSI1) protein [19-21] and Companion of Cellulose Synthase protein 1 and 2 (CC1 and CC2), respectively [22].

Apart from the role of cortical microtubules on cellulose microfibril orientation, several authors supported that CESA activity and cellulose synthesis also exert an effect on cortical microtubule orientation, suggesting thus that cortical microtubule-cellulose microfibril relationship is bi-directional. In particular, experiments with cellulose synthesis inhibitors [23] and genetic analysis of CESA mutants (cesa) revealed that CESA impairment and cellulose deficiency affect cortical microtubule stability and organization (among others [24-26]). In addition, Le et al. showed that exposure to ethylene inhibited cell elongation in $A$. thaliana root tips and consequently altered cortical microtubule orientation [27]. Thorough experiments by Panteris et al. have revealed that the primary factor for microtubule disorientation in mutants with defective cellulose synthesis and plants affected by cellulose synthesis inhibitors is the suppression of cell expansion, which is a direct consequence of cellulose shortage [28, 29].

Even though plenty of data about cortical microtubule orientation and cell wall mechanics are now available, information about the possible relationship of cellulose synthesis and/or cell expansion with cortical microtubule stability, manifested as sensitivity or resistance to depolymerizing drugs, remains scarce. Paredez et al. have shown that prc1-20, an A. thaliana cesa6 mutant, is more sensitive to the microtubule depolymerizing drug oryzalin, than the wild-type [25]. A similar observation has been also reported for the CSI1 mutant, csi1-2, which is defective in cellulose synthesis [30].

In order to further investigate if, apart from prc1-20 [25], mutations in other $A$. thaliana CESA genes affect the sensitivity of cortical microtubules to oryzalin, cesa1, cesa 3 and cesa 6 mutants were examined in the present study. Surprisingly, the cortical microtubules, in the root cells of the mutants reported here, appeared more persistent against oryzalin, compared to the microtubules of the wild-type. Furthermore, to dissect if this increased persistence is due to defective cellulose synthesis or to decreased cell expansion, chemical treatments with DCB (2, 6 dichlorobenzonitrile; inhibitor of cellulose synthesis, [31]) or Congo red (cellulose binding stain; [32, 33]) were also performed. The observations support that the increased persistence of cortical microtubules is associated with inhibition of cell expansion rather than cellulose deficiency.

\section{Methods}

\section{Plant materials and growth conditions}

Arabidopsis thaliana (L). Heynh wild-type, ecotype Columbia (Col), the thanatos (than) semi-dominant cesa 3 mutant and wild-type seedlings expressing the thanatos allele of atcesa3 (Col-0::AtCesA3(P578S), from now on referred as pcesa3 [14]), the mre1 (multiple response expansion1 [34]), the any1 (anisotropy1 [15]), the temperature-sensitive cesal mutant rsw1 (radially swollen1 [9]), the cesa6 mutant prc1-1 (procuste1-1 [10]) and the csi1 mutant pom 2-4 [20] were used in the experiments. Seeds of the aforementioned plant material were surface-sterilized with sodium chlorate $30 \%(\mathrm{v} / \mathrm{v})$ and kept in the dark at $4{ }^{\circ} \mathrm{C}$ for $48-72 \mathrm{~h}$. The seeds were germinated on modified Hoagland 's solution (4 $\mathrm{mM} \mathrm{KNO}_{3}$, $1 \mathrm{mM} \mathrm{Ca}\left(\mathrm{NO}_{3}\right)_{2}, 2 \mathrm{mM} \mathrm{KH}_{2} \mathrm{PO}_{4}, 0.3 \mathrm{mM} \mathrm{MgSO}{ }_{4}, 0.09$ $\mathrm{mM}$ Fe-citrate and $1 \mathrm{~mL} \mathrm{~L}^{-1}$ micronutrients), supplemented with $2 \%(\mathrm{w} / \mathrm{v})$ sucrose and $1 \%(\mathrm{w} / \mathrm{v})$ phytoagar (Duchefa, Haarlem, the Netherlands). Seedlings were grown in Petri dishes placed vertically in a growth chamber at $21 \pm 1{ }^{\circ} \mathrm{C}$, photoperiod of $16 \mathrm{~h}$ light and $8 \mathrm{~h}$ dark and light intensity $120 \mu \mathrm{mol} \mathrm{m}^{-2} \mathrm{~s}^{-1}$.

Wild-type seeds, $r s w 1$ and $p r c 1-1$ were obtained from NASC (Nottingham Arabidopsis Stock Center, University of Nottingham, UK) while the rest of the above seeds were kindly provided as follows: thanatos and pcesa 3 by Dr. Stamatis Rigas, Dr. Gerasimos Daras and Prof. Polydefkis Hatzopoulos; mre1 by Prof. Leonard Pysh; any1 by Prof. Geoffrey Wasteneys; pom 2-4 by Prof. Staffan 
Persson. Chemicals and reagents were purchased from Applichem (Darmstadt, Germany), Merck (Darmstadt, Germany) and Sigma-Aldrich (Seezle, Germany) unless it is referred differently.

\section{Chemical treatments}

Wild-type seedlings, than, pcesa 3 and mre 1 were treated by pouring oryzalin solution over the dishes as well as by transplanting in dishes with solid medium supplemented with oryzalin. The rest of the seedlings were treated only via transplanting in dishes with drug-supplemented medium. After germination, 5-7 day-old seedlings were treated for 4 or $6 \mathrm{~h}$ with oryzalin, either by pouring an aqueous solution of the drug over the seedlings in the Petri dishes, which were continuously shaken on a rocking platform, or by transplanting the seedlings in dishes with medium supplemented with working oryzalin concentration. The final oryzalin concentration was $200 \mathrm{nM}$ (for longer treatment) or $400 \mathrm{nM}$ (for short treatment; readily diluted from a stock solution of $20 \mathrm{mM}$ in dimethyl-sulfoxide). Seedlings of the wild-type as well as of all the mutants, except $r s w 1$, were treated at room temperature. Since $r s w 1$ expresses its cellulose-deficient phenotype at $30^{\circ} \mathrm{C}$, wild-type and $r s w 1$ seedlings remained for $1 \mathrm{~h}$ at a $30^{\circ} \mathrm{C}$ chamber before treatment with oryzalin, which was also performed at $30{ }^{\circ} \mathrm{C}$. In addition, wildtype, than, prc1-1 and any1 seedlings were transplanted to medium containing $2 \mathrm{mM}$ colchicine (a concentration usually applied on plant cells; Panteris et al. and references therein [35]) for $1.5 \mathrm{~h}$.

Furthermore, wild-type seedlings were treated with combined applications of $400 \mathrm{nM}$ DCB (diluted from stock $10 \mathrm{mM}$ in dimethyl-sulfoxide) and $200 \mathrm{nM}$ oryzalin. Specifically, wild-type seedlings grown in Petri dishes were transplanted to medium containing $400 \mathrm{nM}$ DCB for $22 \mathrm{~h}$ and afterwards were transplanted to medium containing $400 \mathrm{nM} \mathrm{DCB}+200 \mathrm{nM}$ oryzalin for another $6 \mathrm{~h}$. Wild-type seedlings transplanted to medium with $400 \mathrm{nM}$ DCB for $28 \mathrm{~h}$ as well as wild-type seedlings transplanted to medium containing $200 \mathrm{nM}$ oryzalin for $6 \mathrm{~h}$ were used as control samples for the combined treatments.

The same procedure was followed for the combined treatment with $10 \mathrm{mg} \mathrm{L}^{-1}$ Congo red (G. Grubler \& Co., Berlin, Germany) and $200 \mathrm{nM}$ oryzalin. Wild-type seedlings transplanted to medium containing $10 \mathrm{mg} \mathrm{L}^{-1}$ Congo red for $28 \mathrm{~h}$ were used as control samples.

\section{Immunolocalization}

Immunolabelling was performed on seedlings untreated or treated as above, with monoclonal rat anti- $\alpha$-tubulin (YOL1/34, AbD Serotec, Kidlington, UK) and FITCanti-rat (developed in goat, Invitrogen, Carlsbad, CA) as primary and secondary antibody, respectively, diluted in PBS (Phosphate buffered saline, $\mathrm{pH}$ 7.4) at 1:40 for wholemount immunofluorescence microscopy. The protocol described in Panteris et al. was applied [29]. The samples were examined with a Zeiss LSM780 confocal laser scanning microscope (CLSM), images were acquired with ZEN2011 software (Carl Zeiss, Munich, Germany), following the manufacturer's instructions. Imaging and processing settings were the same for control and treated samples, both wild-type and mutants.

\section{Fluorescence intensity measurements}

Fluorescence intensity quantifications were performed in maximum projections of serial CLSM sections of root tips, in the transition and fast elongation zone [36], using the ImageJ software [37] according to Pappas et al., using the formula for corrected total cell fluorescence (CTCF) $[36,38]$. A total of at least thirty individual cells from three root tips per treatment were used for the fluorescence intensity calculation ( 10 cells $(n)$ were measured in each root tip). All experiments were performed in three technical and biological repeats. Statistical significance was analyzed by non-parametric Student's t-test, with significance level set at $p<0.005$.

\section{Results and discussion}

\section{Effects of oryzalin on cortical microtubules in cesa 3} mutants

To determine whether mutations in CESA3 subunit affect cortical microtubule stability, microtubule depolymerization by oryzalin was assessed. In this study, $A$. thaliana root apex was classified into four distinct zones, the meristematic, transition (also referred as distal elongation zone), fast elongation (also known as elongation zone) and growth terminating zone, according to Verbelen et al. [39]. Epidermal cells of the transition and fast elongation zone were studied for cortical microtubule stability, since cell divisions in them are scarce and microtubules are uniformly distributed. Besides, as one of the first effects of oryzalin is the disruption of the cell division-specific microtubule arrays [40-43], the meristematic zone was also monitored to verify whether seedlings were affected by the drug. The features revealing cortical microtubule stability or susceptibility in the transition and fast elongation zone were their integrity, as exhibited by the degree of fragmentation, and their density in each cell, as revealed by the relevant fluorescence intensity measurement. The orientation and density of cortical microtubules in wild-type seedlings, as well as in the heterozygous than and homozygous, $r s w 1$ and prc1-1 mutants, have been shown in Panteris et al. [28, 29].

Firstly, we investigated cortical microtubule stability in heterozygous than (cesa3; referred to as than/ + ) 
seedlings. Cortical microtubules of than/+ roots, under any procedure of treatment (see Methods), appeared more stable than those of the wild-type (Figs. 1 and 2). In the meristematic zone of both wild-type and than/+, abnormal cell divisions, disoriented phragmoplasts and incomplete cell walls could be observed (Figs. 1a and c and $2 \mathrm{a}, \mathrm{b}$ ). In transition and fast elongation zone cells of than/+ roots, cortical microtubules were more integral and densely arranged, compared to those of the wild-type (Figs. 1b, d and 2c, d). The integrity of cortical microtubules was further verified by the fluorescence intensity measurements (Fig. 3). Taken together, cortical microtubules appear more stable in than/+ root cells than in those of the wild-type. This indicates that there might be a correlation between cortical microtubule stability and CESA function or cellulose content, as than/+ is characterized by reduced cellulose content and whole plant dwarfism [14].

Subsequently, we investigated whether the increased resistance to oryzalin is restricted to the than/+ mutant only, or it is a general feature of cesa 3 mutants. Therefore, the mre 1 as well as pcesa 3 , a transgenic plant expressing the than allele [14], were treated with $400 \mathrm{nM}$ oryzalin for $4 \mathrm{~h}$. Both mutants exhibited cortical microtubules more persistent against oryzalin than the wild-type. Specifically, in transition and fast elongation zone cells of the mutants, cortical microtubules appeared longer and more integral (Fig. 4b, c) than those of wild-type roots (Fig. 4a). In addition, higher fluorescence intensity, as a result of more tubulin polymers, was observed in the mutants, compared to the wild-type (Additional file 1: Fig. S1), which confirms the presence of more and longer microtubules. These observations indicate that cortical microtubule stability is a common feature among cesa 3 mutants.

\section{The effect of oryzalin on cortical microtubules in cesa 1 and cesa 6 mutants}

In order to examine whether cortical microtubule stability is limited to cesa 3 mutants or it might be a general feature of primary cell wall-related cesa mutants, rsw1 and any1 (cesa1 mutants), as well as prc1-1 (cesa6 mutant) seedlings were treated with $200 \mathrm{nM}$ oryzalin for $6 \mathrm{~h}$. In the transition and fast elongation zones of any1 and prc1-1, more integral microtubules could be observed (Fig. 5b, c), compared to those of wild-type roots. At 30 ${ }^{\circ} \mathrm{C}$, root cells of $r s w 1$ showed reoriented but integral cortical microtubules, after treatment with oryzalin, while wild-type roots exhibited fewer and shorter microtubules under the same treatment (Fig. 5e; cf. 5d). The increased persistence of cortical microtubules against oryzalin in the mutants was also confirmed by fluorescence intensity quantification (Additional file 2: Fig. S2). It can, therefore, be concluded that increased cortical microtubule persistence against oryzalin is a common feature of primary cell wall-related cesa mutants.

Our results are different from those of Paredez et al., who described the prc1-20 (cesa6 mutant) as hypersensitive to oryzalin [25]. This statement was supported by reorientation of cortical microtubules in root cells, as well as by root swelling when exposed to oryzalin. The differences between our findings and the above may be due to different observation approaches and/or the specific criteria for assessing stability. In the above work [25], a GFP-MAP4 marker was used to visualize microtubules, while here $\alpha$-tubulin immunostaining was performed. Microtubule-Associated Protein 4 (MAP4) decorates microtubules and its fusion to GFP allows microtubule visualization [24]. It has been considered that overexpression of GFP-MAP4 fusion proteins may produce an altered developmental phenotype of microtubule dynamics and orientation [24, 44]. In contrast to GFP markers, immunostaining provides more precise and exact microtubule phenotype as it does not interfere with expression and/or function.

In addition, Paredez et al. did not observe any microtubule disassembly but reorientation [25]. In our study, however, cortical microtubules underwent depolymerization without reorientation. In terms of the properties of anti-microtubule drugs, this behavior appears more expected [40] than microtubule reorientation.

\section{The effect of colchicine on cortical microtubules of cesa1, cesa 3 and cesa 6}

In order to further investigate whether the increased cortical microtubule stability of the above cesa mutants is limited to oryzalin or it is generally manifested against anti-microtubule drugs, treatments with colchicine, another microtubule-depolymerizing drug were administered. Colchicine is the most "classic" and "notorious" drug that disrupts microtubules (among others [45, 46]). Wild-type, any1, than/+ and prc1-1 seedlings were treated with $2 \mathrm{mM}$ colchicine for $1.5 \mathrm{~h}$. The concentration of the drug applied was much higher than that of oryzalin, since colchicine was reported to be effective on plants at higher concentrations (among others [45, 47]). All the seedling roots affected by colchicine showed extensive microtubule depolymerization (Fig. 6). The microtubule remnants were scarce and short. However, the fragments of microtubules appeared longer in the mutants than in the wild-type (Fig. 6b-d, cf. 6a). These results were further verified by the fluorescence intensity measurements (Additional file 3: Fig. S3). Increased cortical microtubule stability may thus be considered as a general feature among cesa mutants, irrespective of the drug or the CESA subunit mutation. 


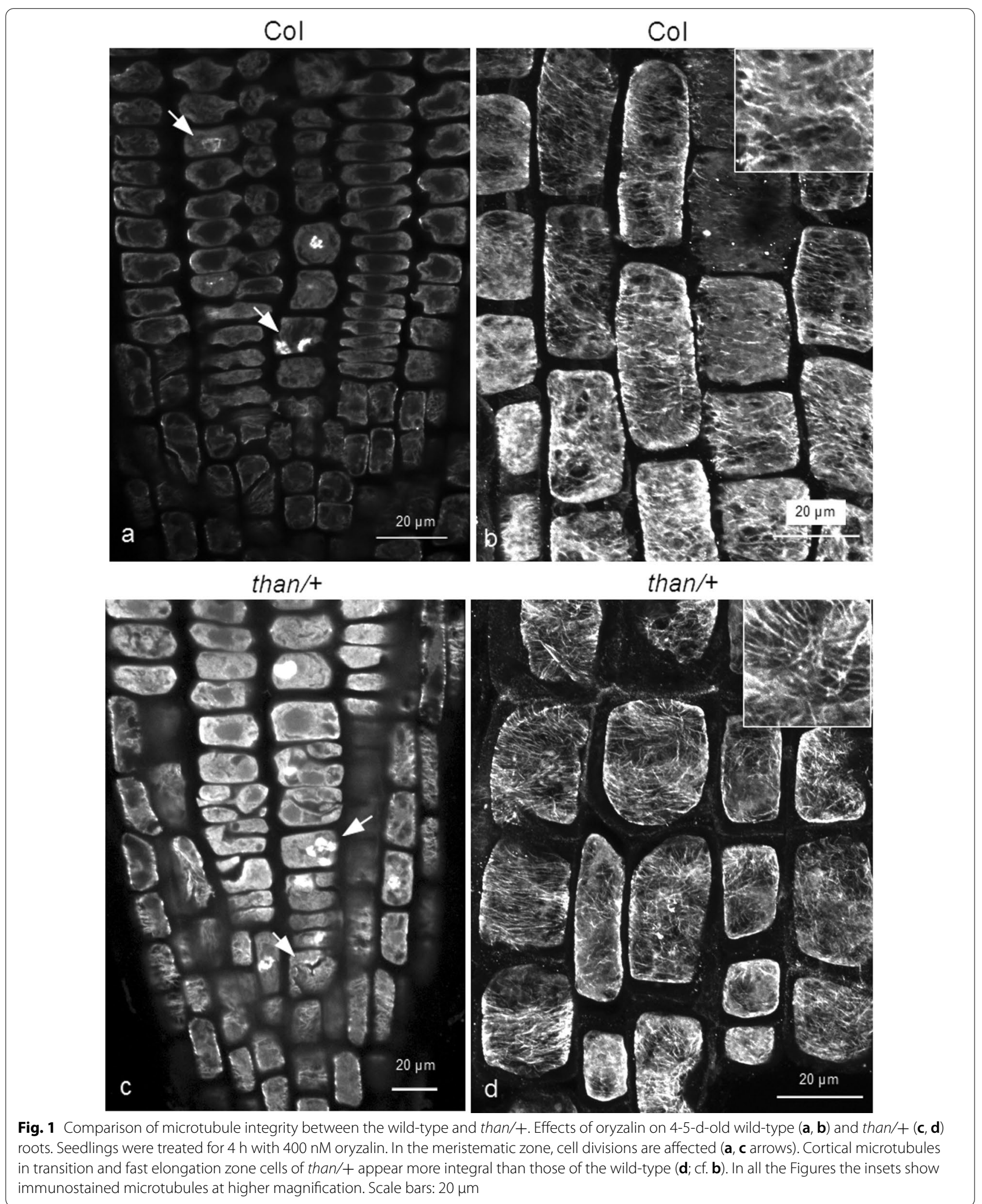




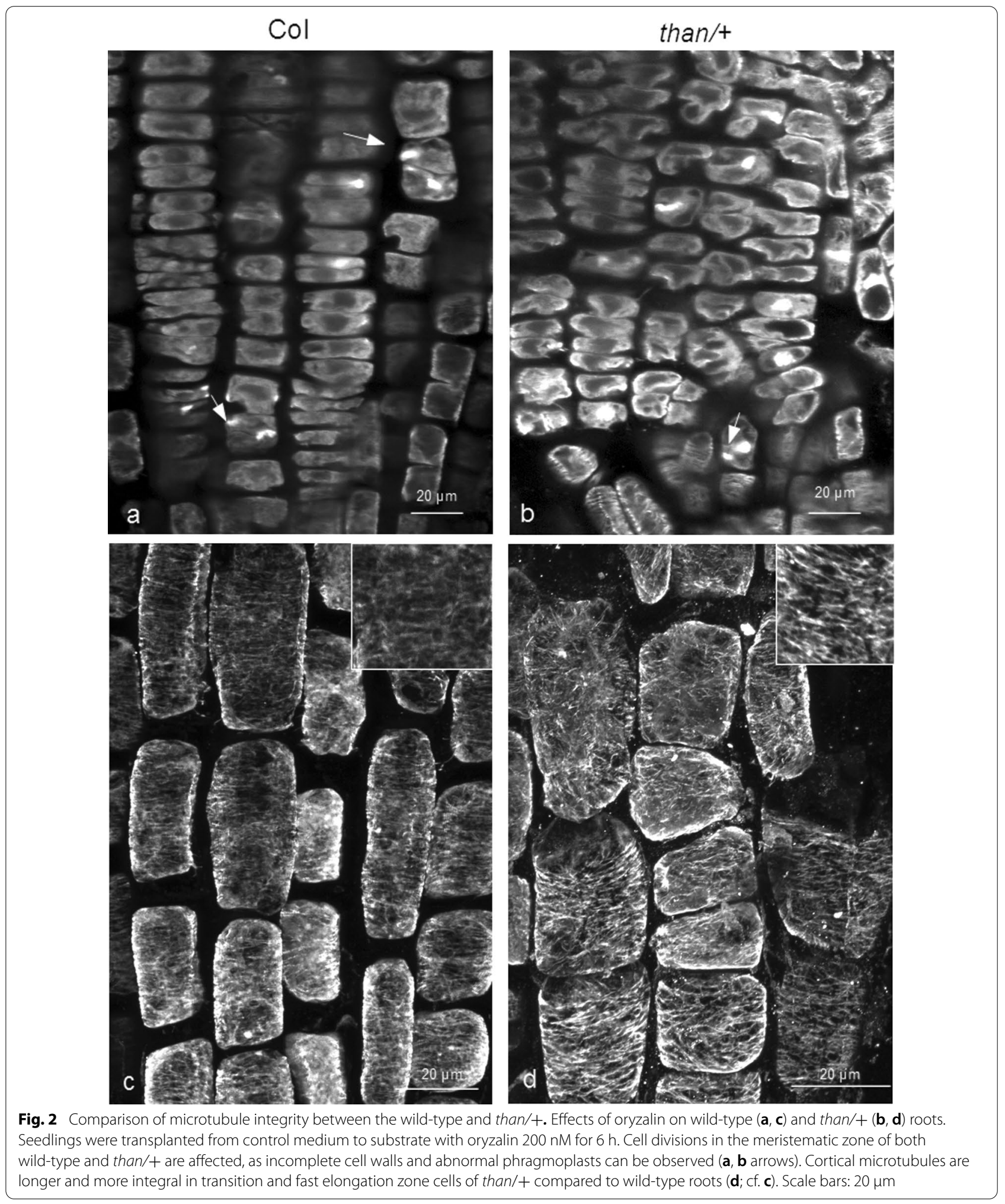

\section{Cortical microtubule stability in the pom 2-4 mutant}

So far, mutants with deficient CESA subunits and decreased cellulose synthesis, except any1, which shows reduced cell wall crystallinity and CESA velocity but physiological cellulose content [15], have been studied. In order to discriminate if the increased microtubule 
a

\section{$400 \mathrm{nM}$ oryzalin $4 \mathrm{~h}$}

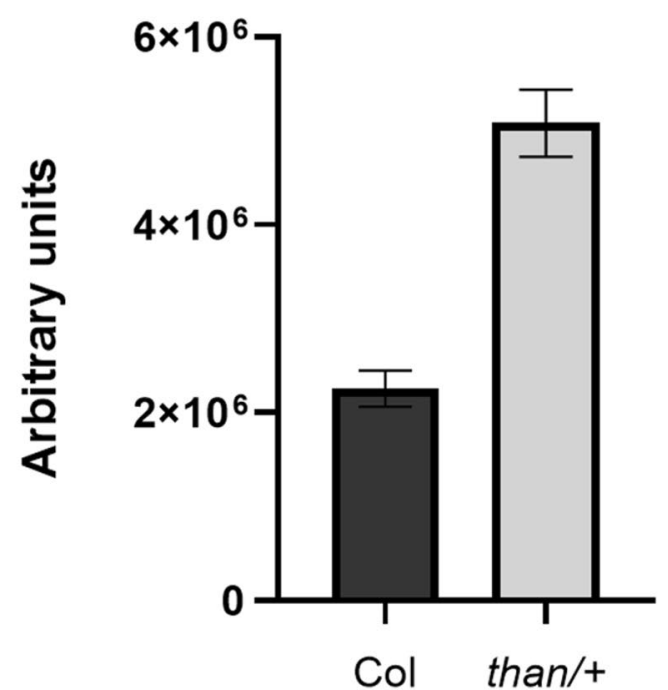

b

\section{$200 \mathrm{nM}$ oryzalin $6 \mathrm{~h}$}

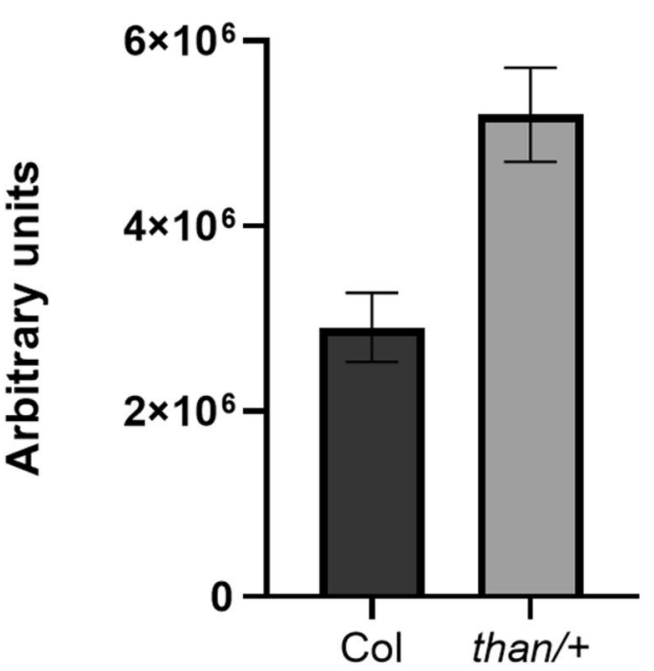

Fig. 3 Fluorescence intensity measurements of cortical microtubules in the transition and fast elongation zone of wild-type and than/+ roots. Maximum intensity projections of serial CLSM sections of transition zone and fast elongation zone were used. Increased fluorescence intensity in than/+ was observed. (a) Effect of $4 \mathrm{~h}$ treatment with $400 \mathrm{nM}$ oryzalin. (b) Effect of oryzalin on roots transplanted from control medium to substrate with oryzalin $200 \mathrm{nM}$ for $6 \mathrm{~h}$. Error bars indicate standard error. The intensity difference was statistically significant compared to control group (oryzalin-treated Col) (t-test, $p<0.001, n=10$ ). In all the figures the $n$ corresponds to the number of cells measured in each root tip. At least three root tips were used for fluorescence intensity measurements

stability resulted from malfunction of the CESAs per se or from defective cellulose synthesis, the csi1 mutant pom24 was treated with oryzalin. In this csil mutant, defects in growth and cell expansion occur due to decreased cellulose content, although the CESA subunits are normal $[19,20,48]$. After treatment with $200 \mathrm{nM}$ oryzalin for $6 \mathrm{~h}$, cell divisions appeared affected in the meristematic zone of both wild-type and pom 2-4 roots (Fig. $7 \mathrm{a}, \mathrm{c}$ ). In transition and fast elongation zone of roots treated as above, cortical microtubules of pom 2-4 appeared longer and more integral, in comparison with those of the wildtype (Fig. 7d, cf. 7b). Increased fluorescence intensity was observed in pom2-4, as well (Additional file 2: Fig. S2). Contrarily to our results, Mei et al. reported that cortical microtubules in hypocotyl cells of csi1-2 were more sensitive to oryzalin than those of the wild-type [30]. However, their observations were made by GFP-MAP4 imaging, which may affect microtubule properties and behavior (see above). In addition, root cells may react differently to oryzalin than hypocotyl cells. Taken together, our observations support that increased cortical microtubule stability, which is common in cesa and csil mutants, should rather be attributed not to CESA malfunction per $s e$, but to decreased cellulose content in the cell wall.

\section{Inhibition of cellulose synthesis increases cortical microtubule stability in wild-type seedlings}

To address the question whether defective cellulose biosynthesis may improve cortical microtubule stability, wild-type roots were examined after combined treatment with DCB and oryzalin. DCB is a synthetic herbicide causing cessation of CESA complex movement, resulting in inhibition of cellulose synthesis and deposition (among others $[49,50])$. For this experiment, 4-dold wild-type seedlings were transferred to a medium containing $400 \mathrm{nM} \mathrm{DCB}$ for $22 \mathrm{~h}$ and then transferred to medium with $400 \mathrm{nM} \mathrm{DCB}$ and $200 \mathrm{nM}$ oryzalin for $6 \mathrm{~h}$. Seedlings treated for $6 \mathrm{~h}$ with $200 \mathrm{nM}$ oryzalin alone were used as control (Fig. 8). Root tip bulging and inhibition of seedling growth was observed in DCB and combined DCB and oryzalin treatment (Additional file 4: Fig. S4). Abnormal cell divisions and incomplete cell walls in oryzalin and in the combined treatment prove the effect of oryzalin in the roots (Fig. 8a, b). The length of all root cell types appeared affected after treatment with DCB, and the cells appeared shorter and flattened, compared to untreated root cells (Fig. 8b; cf. 8a, 8d, 8e; cf. 8c). As shown in Fig. 8d, DCB did not affect cortical microtubules. Wild-type roots subjected to combined 

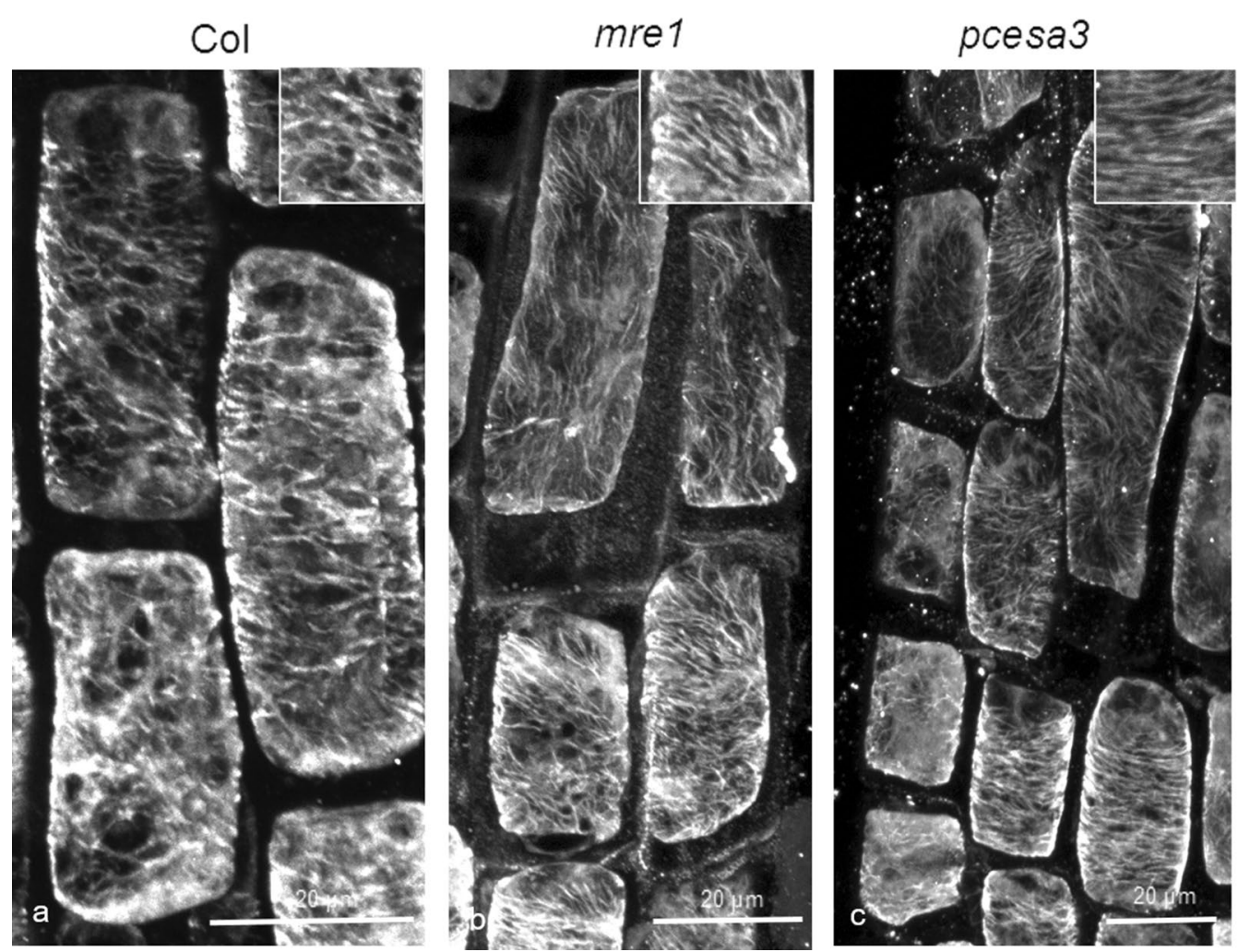

Fig. 4 Comparison of microtubule integrity between the wild-type and mre1 and pcesa3. Effects of $4 \mathrm{~h}$ treatment with $400 \mathrm{nM}$ oryzalin on 4-5-d-old wild-type (a), mrel (b) and pcesa3 (c) roots. In both mutants (b, c) cortical microtubules of transition and fast elongation zone cells appear longer and more integral, compared to those of wild-type roots (a). Scale bars: $20 \mu \mathrm{m}$

treatment exhibited cortical microtubules as integral as roots treated with DCB only in the transition and fast elongation zones (Fig. 8e; cf. 8d), not depolymerized as in oryzalin-treated roots (Fig. 8c). Increased fluorescence intensity was observed in DCB and combined DCB and oryzalin treatments compared to the control (Fig. 9).

\section{Inhibition of cell expansion results in more stable cortical} microtubules in the transition and fast elongation zones

A common feature of cellulose-deficient mutants, as well as of DCB-treated wild-type seedlings, is the inhibition of cell elongation $[9,10,14,34,49]$. In addition, although the any1 mutant of cesa 1 is characterized by normal cellulose content, it exhibits decreased cell elongation due to defective cellulose crystallinity [15]. In order to clarify whether inhibition of cell elongation might be the main cause for increased microtubule stability, the effect of Congo red, a dye that inhibits cell expansion, was investigated (Fig. 10). Congo red, binds to cellulose without affecting its biosynthesis but preventing glucan chain crystallization and, consequently, typical microfibril formation [32, 33, 51]. Wild-type seedlings were treated either with $200 \mathrm{nM}$ oryzalin for
$6 \mathrm{~h}$, or they were first transplanted for $22 \mathrm{~h}$ to medium supplemented with $10 \mathrm{mg} \mathrm{L}^{-1}$ Congo red and then transplanted to medium containing $10 \mathrm{mg} \mathrm{L}^{-1}$ Congo red and $200 \mathrm{nM}$ oryzalin for $6 \mathrm{~h}$. Root tips of seedlings treated with Congo red or Congo red and oryzalin exhibited intense curling (Additional file 4: Fig. S4). Abnormal cell divisions observed in both oryzalin and combined treatments revealed the depolymerizing effect of oryzalin (Fig. 10a, b). Congo red application resulted in decreased cell elongation in the root apex developmental zones without affecting cortical microtubules (Fig. 10d). After the combined Congo red and oryzalin treatment, cortical microtubules in transition and fast elongation zone cells appeared integral and almost unaffected by oryzalin (Fig. 10e; cf. 10d), in contrast to those of roots treated with oryzalin alone, in which cortical microtubules appeared fragmented and partially depolymerized (Fig. 10c). The increased integrity in Congo red and combined Congo red and oryzalin treatments, compared to the control, was verified by fluorescence intensity measurements (Fig. 9) and was found statistically significant $(p<0.0001)$. According to these findings, it may be concluded that inhibition 


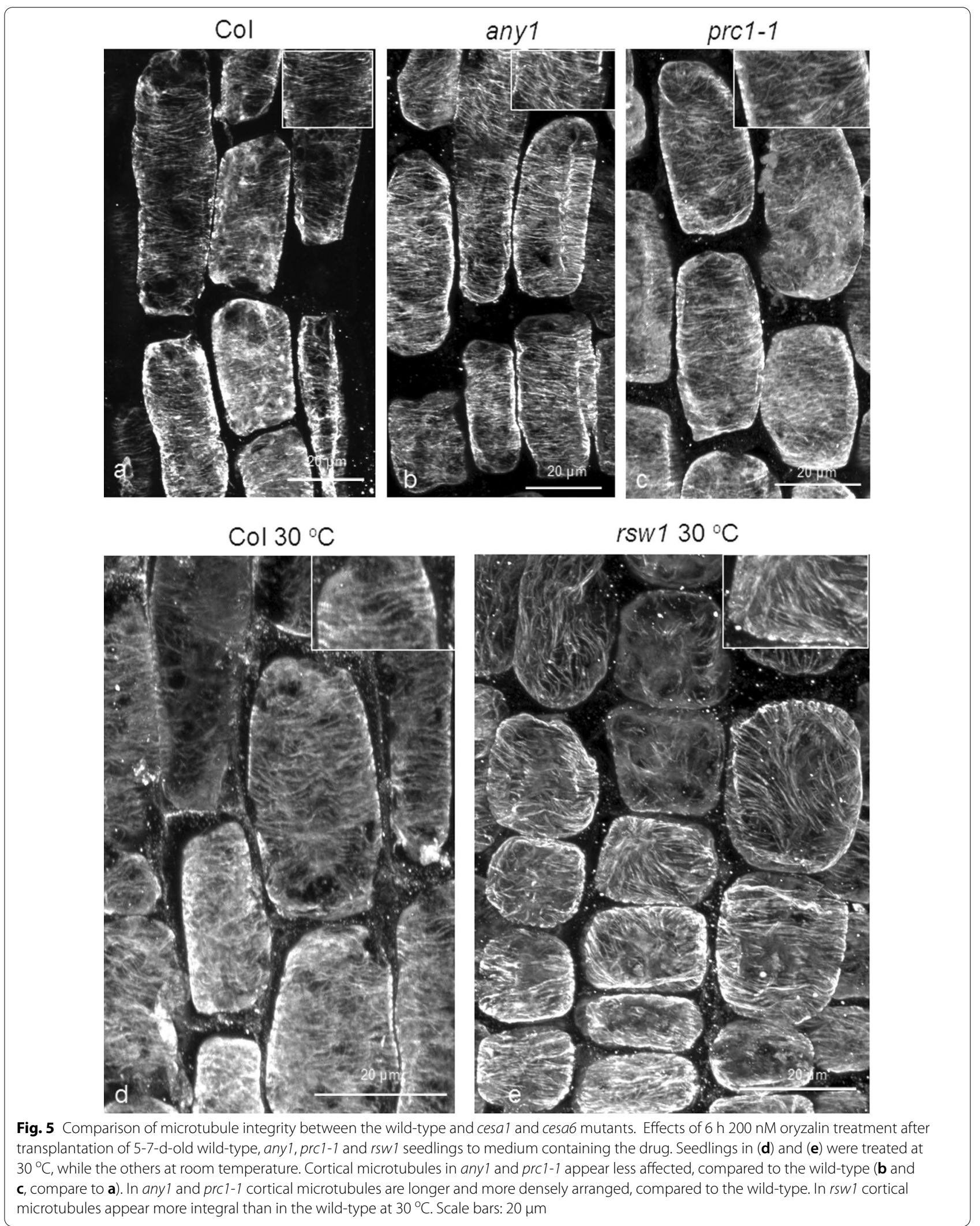




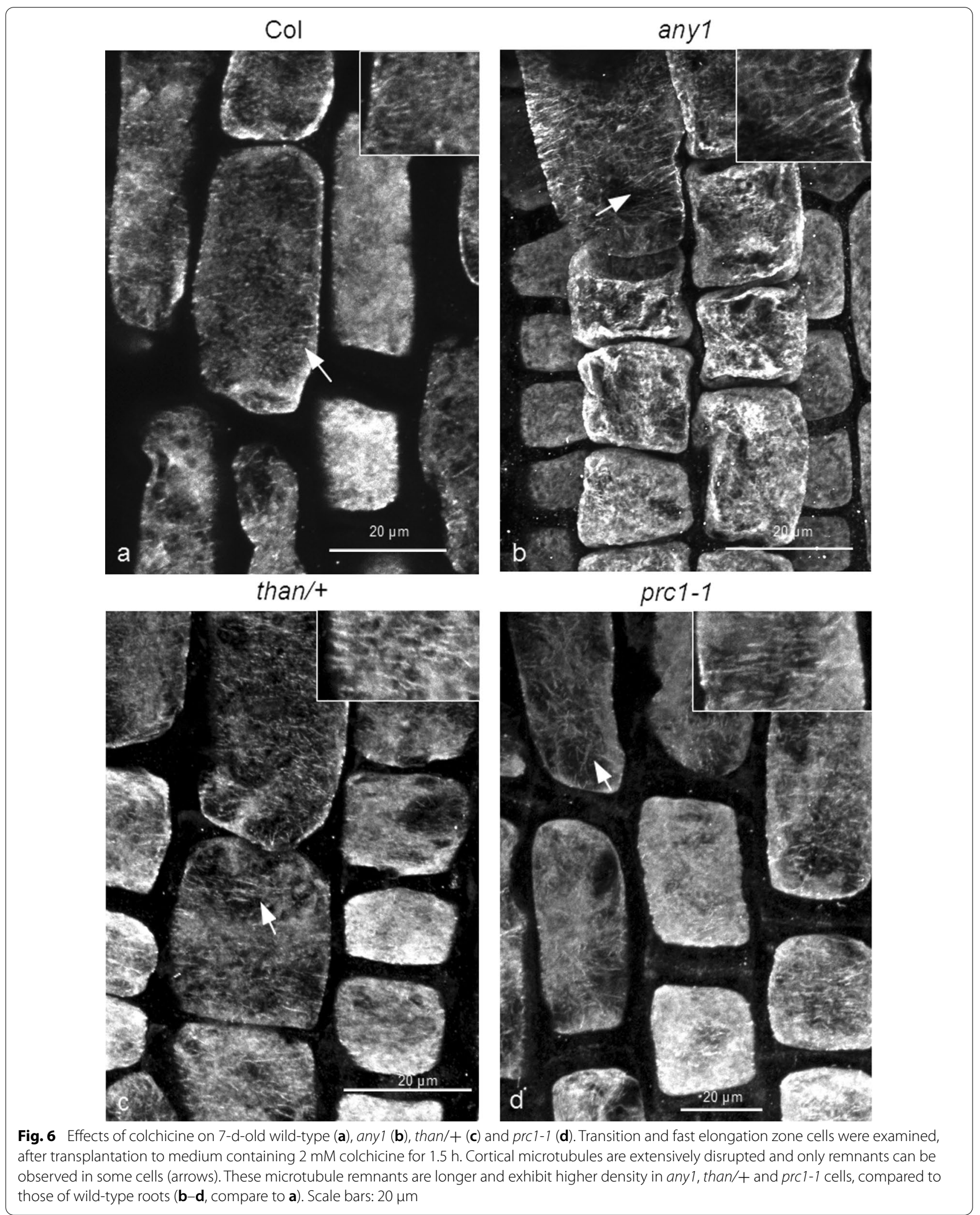




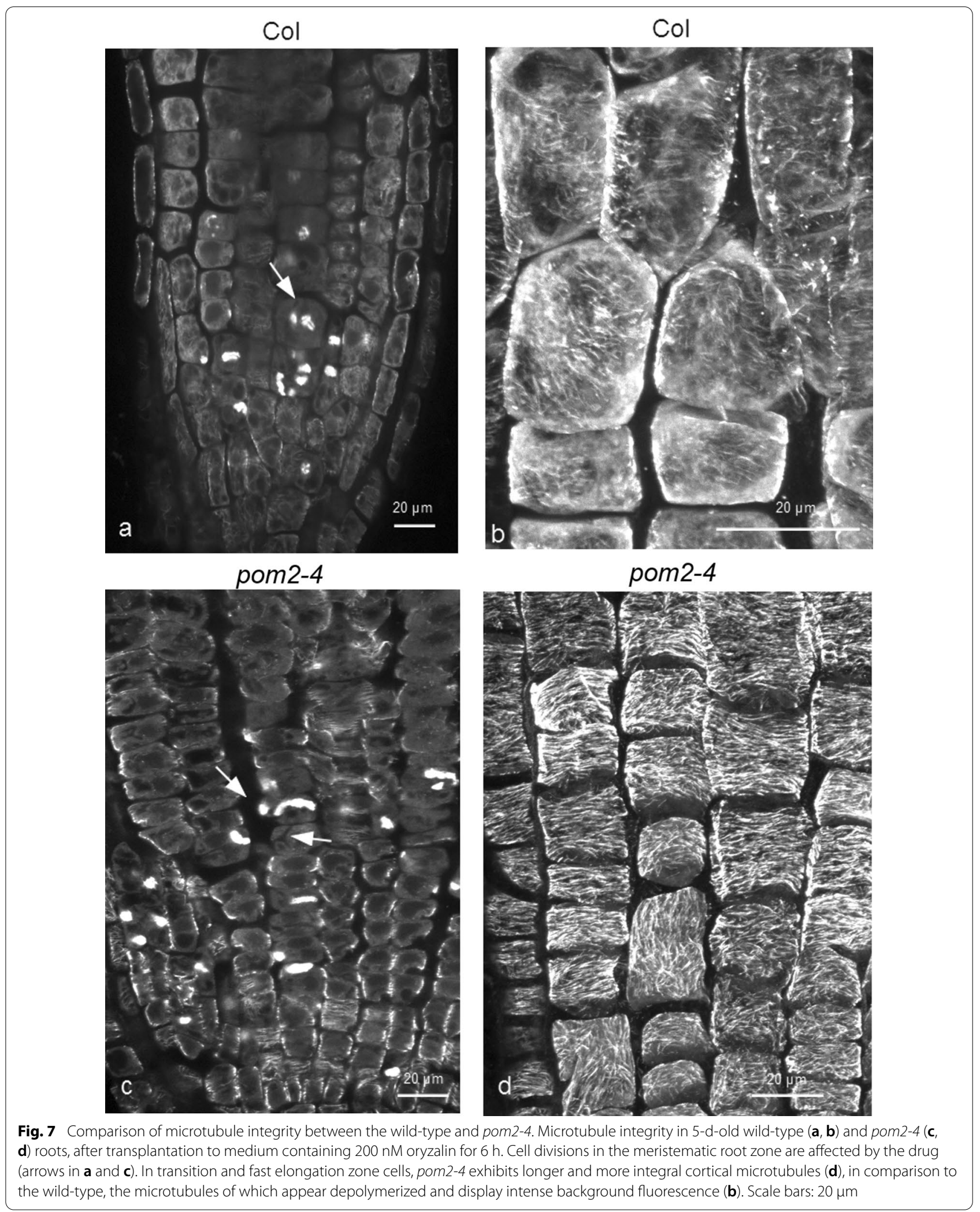




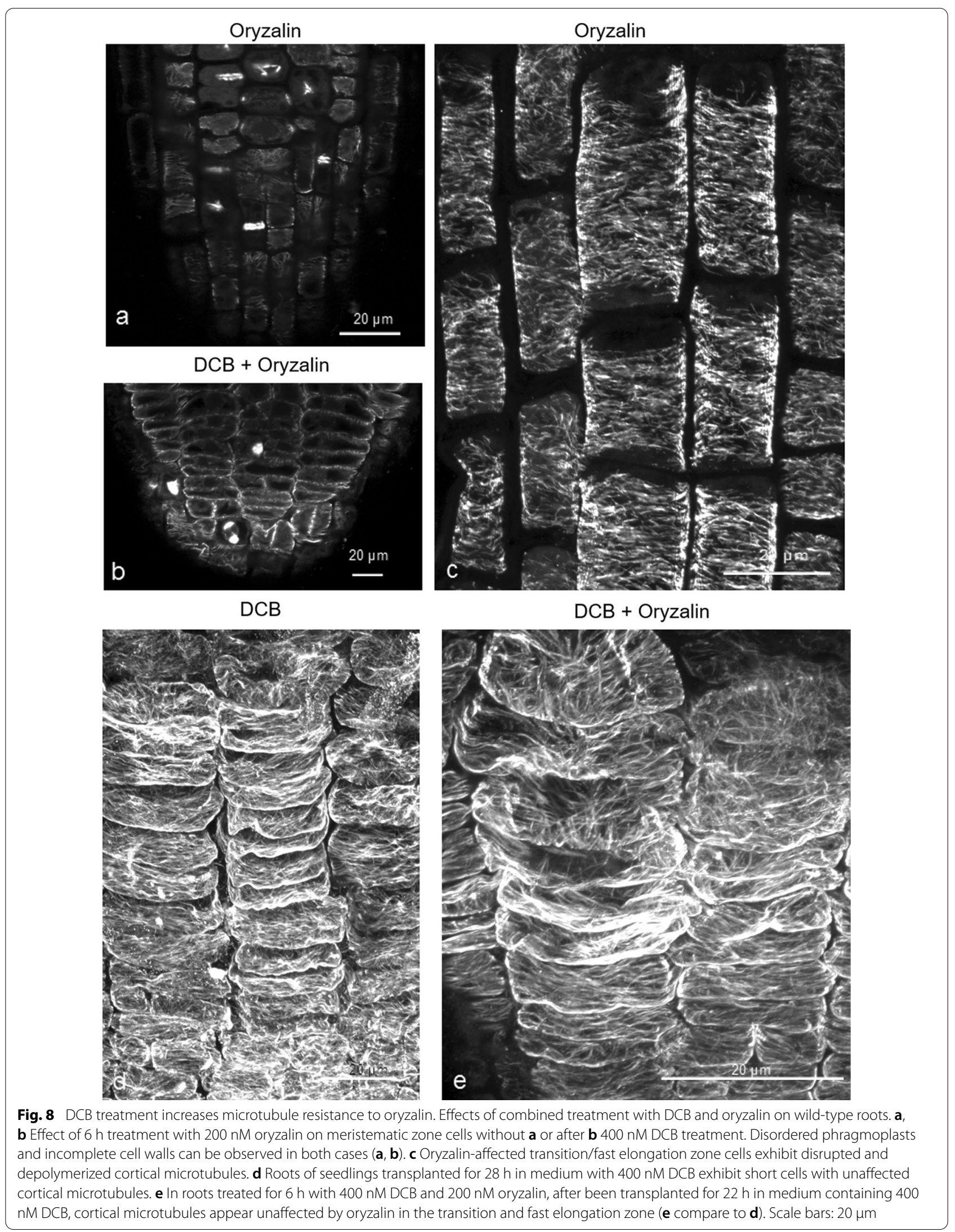




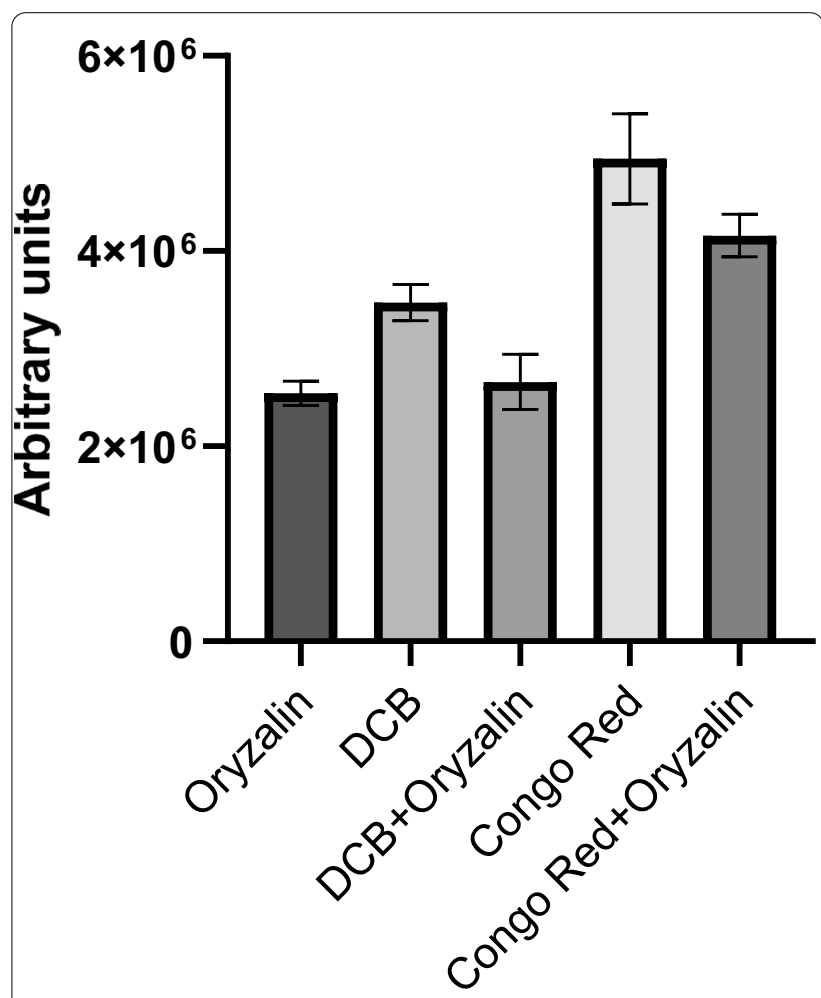

Fig. 9 Fluorescence intensity measurements of cortical microtubules of wild-type roots. Prior to $200 \mathrm{nM}$ oryzalin treatment for $6 \mathrm{~h}$, seedlings were transplanted to media containing either 400 nM DCB for $28 \mathrm{~h}$ or $10 \mathrm{mg} \mathrm{L}^{-1}$ Congo red for $22 \mathrm{~h}$. Oryzalin-treated seedlings showed the lowest fluorescence intensity. The fluorescence intensity difference was statistically significant for DCB, Congo red and combined treatment of Congo red and oryzalin, compared to the control $(p<0.0001, n=10)$. No statistical significance was observed for intensity fluorescence when oryzalin-treated and combined oryzalin- and DCB-treated roots were compared ( $p=0.6835, n=10)$. Error bars indicate standard error

of cell expansion, irrespective of the cause, results in increased microtubule stability.

Fisher and Cyr were the first to describe a bidirectional relationship between cortical microtubules and the cell wall [23]. According to them, the mechanical properties of cell wall, rather than cellulose biosynthesis, affect cortical microtubule stability and organization. When Nicotiana tabacum BY-2 protoplasts were treated with isoxaben (a cellulose biosynthesis inhibitor), microtubules were randomly organized. Cultivation in the absence of isoxaben resulted in highly organized cortical microtubules [23]. Since then, it was supported by several authors that cellulose biosynthesis provides spatial cues for cortical microtubule organization. Chu et al. and Paredez et al. reported alterations in cortical microtubule organization and stability in cesa mutants, concluding that cellulose synthesis may play a regulatory role in microtubule organization [24, 25]. On the other hand, Le et al. supported that inhibition of cell elongation in ethylene-treated roots results in microtubule reorientation [27]. In agreement with the latter work, Panteris et al., have demonstrated that chemical, mechanical or genetic inhibition of cell expansion affects cortical microtubule orientation in A. thaliana root apex, supporting the bidirectional relationship of cell wall and cortical microtubules $[28,29]$.

The results of this study support that cell expansion is associated not only with cortical microtubule orientation $[28,29]$ but also with microtubule stability. The common feature among cesa mutants (any1, rsw1, than/+, mre1, prc1-1), csi1 mutant (pom2-4), DCB and Congo red treatments is that, in all cases, cell expansion is negatively affected. More specifically, decreased cellulose biosynthesis, either caused by CESA malfunction (any1, rsw1, than/+, mre1, prc1-1 and DCB), or by CSI1 (pom2-4) mutation, results in inhibition of cell elongation $[9,10,14$, $34,48-50]$. On the other hand, Congo red prevents cellulose crystallization [32,33], while any1 shows altered cell wall crystallinity [15]. In conclusion, apart from inducing cortical microtubule reorientation [28, 29], inhibition of cell expansion enhances cortical microtubule stability.

Various hypotheses may explain the increased cortical microtubule stability under decreased cell expansion. It has been reported that cell wall sensors allow cortical microtubules to detect and respond to stress signals [52, 53]. Such sensors include the THESEUS kinase, which is responsible for detecting cellulose deficiency, irrespective the cause, and acting as a cell wall integrity sensor [54]. In addition, another kinase, FERONIA, was reported to be important for cell wall integrity perception, in relation to cell and whole plant growth [55]. According to another hypothesis, it may be possible that, due to decreased cell expansion, cortical microtubules become more stationary. New cellulose microfibrils are deposited during cell elongation, between the existing ones [56]. Concurrently, newly-formed microtubules are recruited to maintain the density of cortical microtubule array. When cell expansion is decreased, the above procedure pertains at slow rate, possibly exerting a pausing effect on cortical microtubules, which remain stable, also interconnected by MAP bridges [57]. As a result, tubulin dimers are not released, while new ones are not added: consequently, tubulin-binding anti-microtubule drugs, such as oryzalin and colchicine exert a less pronounced effect on microtubules.

\section{Conclusions}

This study provides evidence that inhibition of cell expansion, irrespective of the cause, enhanced the stability of cortical microtubules. It is therefore supported that 


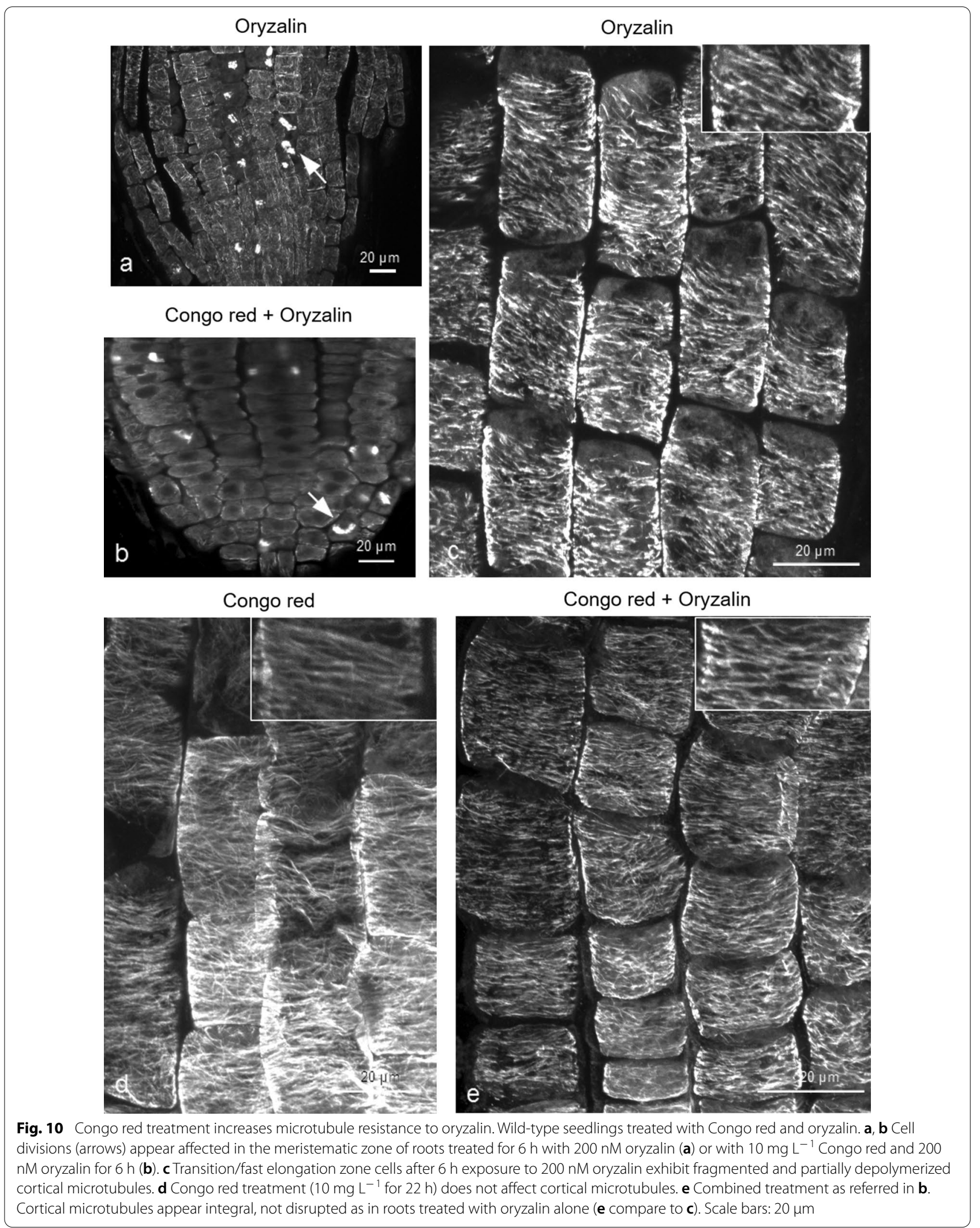


a bidirectional relationship between cell expansion and microtubule stability exists. Further work is required to elucidate the mechanisms underlying this bidirectional relationship.

\begin{abstract}
Abbreviations
CESA: Cellulose Synthase A; CSC: Cellulose Synthase Complex; CSI1: Cellulose Synthase Interacting 1 protein; CC1: Companion of Cellulose Synthase protein 1; CC2: Companion of Cellulose Synthase protein 2; prc1-20: Procuste1-20; than: Thanatos; than/+: Heterozygous than; DCB: 2, 6 dichlorobenzonitrile.; rsw 1 : Radially swollen 1; prc 1-1: Procuste1-1; mre1: Multiple response expansion 1; pcesa3: Transgenic plant expressing the than allele; any1: Anisotropy1; GFP: Green fluorescent protein; MAP: Microtubule-associated protein; CLSM: Confocal laser scanning microscope; CTCF: Corrected total cell fluorescence.
\end{abstract}

\section{Supplementary Information}

The online version contains supplementary material available at https://doi. org/10.1186/s40709-021-00143-8.

Additional file 1: Figure S1. Fluorescence intensity measurements of cortical microtubules in wild type and cesa 3 mutant roots: mrel and pcesa 3 roots were treated with $400 \mathrm{nM}$ oryzalin for $4 \mathrm{~h}$. Maximum intensity projections of serial CLSM sections were used. Increased intensity was observed in both mutants, compared to the wild type. Error bars indicated standard error. Fluorescence intensity was measured in totally 30 individual cells of 3 wild type roots and 20 individual cells from 2 roots of mre 1 and pcesa3 mutants.

Additional file 2: Figure S2. Fluorescence intensity measurements of cortical microtubules in wild type, any 1, prc1-1, pom2-4 and rsw 1 roots. Seedlings were transplanted from control medium to substrate containing $200 \mathrm{nM}$ oryzalin for $6 \mathrm{~h}$. Prior to treatment with oryzalin, some seedlings of the wild type and $r s w 1$ mutant were incubated at $30^{\circ} \mathrm{C}$ for $1 \mathrm{~h}$. Increased fluorescence intensity was observed in all mutants, compared to the respective control. The fluorescence intensity difference for any 1 and prc1-1 was statistically significant compared to control $(p<0.0001, n=$ $10)$ as well for rsw 1 compared to control $(p<0.001, n=10)$. No statistical significance was observed for pom2-4 compared to control $(p=0.13, n=$ 10). The $n$ value corresponds to number of cells measured in each root tip. At least 3 root tips were used for each measurement. Error bars indicate standards errors.

Additional file 3: Figure S3. Fluorescence intensity measurements of cortical microtubules in seedling roots treated with colchicine. The wild type and the mutants any 1, than/+ and prc1-1 were transplanted from control medium to substrate supplemented with $2 \mathrm{mM}$ colchicine for 1.5 h. Increased fluorescence intensity was observed in the mutants, compared to the wild type. The than/+ mutants exhibited the highest fluorescence intensity which was statistically significant compared to treated wild type ( $p<0.05, n=10$ ). The fluorescence intensity of any 1 and prc $1-1$ were not statistically significant compared to control $(p=0.12, n=10$ for both mutants). The $n$ value corresponds to number of cells measured in each root tip. At least 3 root tips were used for each measurement. Error bars represent standard errors.

Additional file 4: Figure S4. Effects of chemical treatments (DCB or Congo red and oryzalin) on root growth. 4 to 5-day old wild type seedlings were grown vertically on Petridishes and subsequently transplanted to media supplemented with $400 \mathrm{nM} \mathrm{DCB}\left(22 \mathrm{~h}\right.$ treatment) or $10 \mathrm{mg} \mathrm{L}^{-1}$ Congo red ( $22 \mathrm{~h}$ treatment) and then transferred to media containing additionally $200 \mathrm{nM}$ oryzalin for $6 \mathrm{~h}$. Root tip swelling and curling were observed in DCB and Congo red treated seedlings, respectively. Chemicals were applied as shown in Methods. Scale bar: $1 \mathrm{~mm}$.

\section{Authors' contributions}

VG performed the experiments and wrote the manuscript. EP designed and supervised all the experiments and wrote the manuscript. Both authors read and approved the final manuscript.

\section{Funding}

EP was supported by AUTh Research Committee, Grant No. 91913.

\section{Availability of data and materials}

All data generated during this study are included in this published article manuscript and its Additional files.

\section{Declarations}

Ethics approval and consent to participate

Not applicable.

\section{Consent for publication}

Not applicable.

\section{Competing interests}

The authors declare that they have no competing interests.

\section{Author details}

'Department of Botany, School of Biology, Aristotle University of Thessaloniki, 54124 Thessaloniki, Greece. ${ }^{2}$ Laboratory of Biochemistry, School of Chemistry, Aristotle University of Thessaloniki, 54124 Thessaloniki, Greece.

Received: 20 October 2020 Accepted: 18 May 2021

Published online: 03 June 2021

\section{References}

1. Elliott A, Shaw SL. Update: plant cortical microtubule arrays. Plant Physiol. 2018;176:94-105.

2. Smith LG, Oppenheimer DG. Spatial control of cell expansion by the plant cytoskeleton. Annu Rev Cell Dev Biol. 2005;21:271-95.

3. Szymanski DB, Cosgrove DJ. Dynamic coordination of cytoskeletal and cell wall systems during plant cell morphogenesis. Curr Biol. 2009;19:R800-11.

4. Ledbetter MC, Porter KR. A "microtubule" in plant cell fine structure. J Cell Biol. 1963;19:239-50.

5. Paredez AR, Somerville CR, Ehrhardt DW. Visualization of cellulose synthase demonstrates functional association with microtubules. Science. 2006;312:1491-5.

6. Somerville C. Cellulose synthesis in higher plants. Annu Rev Cell Dev Biol. 2006;22:53-78.

7. Holland N, Holland D, Helentjaris T, Dhugga KS, Xoconostle-Cazares B, Delmer DP. A comparative analysis of the plant cellulose synthase (CesA) gene family. Plant Physiol. 2000;123:1313-24.

8. Richmond T. Higher plant cellulose synthases. Genome Biol. 2000;1:reviews3001.

9. Arioli T, Peng L, Betzner AS, Burn J, Wittke W, Herth W, et al. Molecular analysis of cellulose biosynthesis in Arabidopsis. Science. 1998;279:717-20.

10. Fagard M, Desnos T, Desprez T, Goubet F, Refregier G, Mouille G, et al. PROCUSTE1 encodes a cellulose synthase required for normal cell elongation specifically in roots and dark-grown hypocotyls of Arabidopsis. Plant Cell. 2000;12:2409-23.

11. Scheible W-R, Eshed R, Richmond T, Delmer D, Somerville C. Modifications of cellulose synthase confer resistance to isoxaben and thiazolidinone herbicides in Arabidopsis Ixr1 mutants. Proc Natl Acad Sci USA. 2001;98:10079-84.

\section{Acknowledgements}

We kindly thank all the colleagues that provided plant material. 
12. Desprez T, Juraniec M, Crowell EF, Jouy H, Pochylova Z, Parcy F, et al. Organization of cellulose synthase complexes involved in primary cell wall synthesis in Arabidopsis thaliana. Proc Natl Acad Sci USA. 2007;104:15572-7.

13. Persson S, Paredez A, Carroll A, Palsdottir H, Doblin M, Poindexter P, et al. Genetic evidence for three unique components in primary cell-wall cellulose synthase complexes in Arabidopsis. Proc Natl Acad Sci USA 2007;104:15566-71.

14. Daras G, Rigas S, Penning B, Milioni D, McCann MC, Carpita NC, et al. The thanatos mutation in Arabidopsis thaliana cellulose synthase 3 (AtCesA3) has a dominant-negative effect on cellulose synthesis and plant growth. New Phytol. 2009;184:114-26.

15. Fujita M, Himmelspach R, Ward J, Whittington A, Hasenbein N, Liu C, et al. The anisotropy 1 D604N mutation in the Arabidopsis cellulose synthase1 catalytic domain reduces cell wall crystallinity and the velocity of cellulose synthase complexes. Plant Physiol. 2013;162:74-85.

16. Heath IB. A unified hypothesis for the role of membrane bound enzyme complexes and microtubules in plant cell wall synthesis. JTheor Biol. 1974:48:445-9.

17. Baskin TI. On the alignment of cellulose microfibrils by cortical microtubules: A review and a model. Protoplasma. 2001:215:150-71.

18. Giddings TH, Staehelin LA. Microtubule-mediated control of microfibril deposition: a re-examination of the hypothesis. In: Lloyd CW, editor. The cytoskeletal basis of plant growth and form. San Diego: Academic Press; 1991. pp. 85-99.

19. Gu Y, Kaplinsky N, Bringmann M, Cobb A, Carroll A, Sampathkumar A, et al. Identification of a cellulose synthase-associated protein required for cellulose biosynthesis. Proc Natl Acad Sci USA. 2010;107:12866-71.

20. Bringmann M, Li E, Sampathkumar A, KocabekT, Hauser M, Persson S. POMPOM2/CELLULOSE SYNTHASE INTERACTING1 is essential for the functional association of cellulose synthase and microtubules in Arabidopsis. Plant Cell. 2012:24:163-77.

21. Lei L, Li S, Gu Y. Cellulose synthase interactive protein 1 (CSI1) mediates the intimate relationship between cellulose microfibrils and cortical microtubules. Plant Signal Behav. 2012;7:714-8.

22. Endler A, Kesten C, Schneider R, Zhang Y, Ivakov A, Froehlich A, et al. A mechanism for sustained cellulose synthesis during salt stress. Cell. 2015;162:1353-64.

23. Fisher DD, Cyr RJ. Extending the microtubule/microfibril paradigm cellulose synthesis is required for normal cortical microtubule alignment in elongating cells. Plant Physiol. 1998;116:1043-51.

24. Chu Z, Chen H, Zhang Y, Zhang Z, Zheng N, Yin B, et al. Knockout of the AtCESA2 gene affects microtubule orientation and causes abnormal cell expansion in Arabidopsis. Plant Physiol. 2007;143:213-24.

25. Paredez AR, Persson S, Ehrhardt DW, Somerville CR. Genetic evidence that cellulose synthase activity influences microtubule cortical array organization. Plant Physiol. 2008;147:1723-34.

26. Peng L, Zhang L, Cheng X, Fan L-S, Hao H-Q. Disruption of cellulose synthesis by 2,6-dichlorobenzonitrile affects the structure of the cytoskeleton and cell wall construction in Arabidopsis. Plant Biol. 2013;15:405-14.

27. Le J, Vandenbussche F, Van Der Straeten D, Verbelen J. Position and cell type-dependent microtubule reorientation characterizes the early response of the Arabidopsis root epidermis to ethylene. Physiol Plant. 2004;121:513-9.

28. Panteris E, Adamakis IS, Daras G, Rigas S. Cortical microtubule patterning in roots of Arabidopsis thaliana primary cell wall mutants reveals the bidirectional interplay with cell expansion. Plant Signal Behav. 2015;9:e28737.

29. Panteris E, Adamakis IS, Daras G, Hatzopoulos P, Rigas S. Differential responsiveness of cortical microtubule orientation to suppression of cell expansion among the developmental zones of Arabidopsis thaliana root apex. PLoS One. 2013;8:e82442.

30. Mei Y, Gao H, Yuan M, Xue H. The Arabidopsis ARCP protein, CSI1, which is required for microtubule stability, is necessary for root and anther development. Plant Cell. 2012:24:1066-80.

31. Montezinos D, Delmer D. Characterization of inhibitors of cellulose synthesis in cotton fibers. Planta. 1980;148:305-11.

32. Wood P. Specificity in the interaction of direct dyes with polysaccharides. Carbohydr Res. 1980;85:271-87.

33. Wood PJ, Fulcher RG. Dye interactions. A basis for specific detection and histochemistry of polysaccharides. J Histochem Cytochem. 1983;31:823-6.
34. Pysh L, Alexander N, Swatzyna L, Harbert R. Four alleles of AtCESA3 form an allelic series with respect to root phenotype in Arabidopsis thaliana. Physiol Plant. 2012:144:369-81.

35. Panteris E, Komis G, Adamakis I-DS, Šamaj J, Bosabalidis AM. MAP65 in tubulin/colchicine paracrystals of Vigna sinensis root cells: Possible role in the assembly and stabilization of atypical tubulin polymers. Cytoskeleton. 2010;67:152-60.

36. Pappas D, Gkelis S, Panteris E. The effects of microcystin-LR in Oryza sativa root cells: F-actin as a new target of cyanobacterial toxicity. Plant Biol. 2020;22:839-49.

37. Schneider CA, Rasband WS, Eliceiri KW. NIH Image to ImageJ: 25 years of image analysis. Nat Methods. 2012;9:671-5.

38. Gavet O, Pines J. Activation of cyclin B1-Cdk1 synchronizes events in the nucleus and the cytoplasm at mitosis. J Cell Biol. 2010;189:247-59.

39. Verbelen J-P, Cnodder T, De, Le J, Vissenberg K, Baluška F. The root apex of Arabidopsis thaliana consists of four distinct zones of growth activities. Plant Signal Behav. 2006;1:296-304.

40. Morejohn LC, Bureau TE, Mole-Bajer J, Bajer AS, Fosket DE. Oryzalin, a dintroaniline herbicide, binds to plant tubulin and inhibits microtubule polymerization in vitro. Planta. 1987;172:252-64.

41. Anthony RG, Hussey PJ. Dinitroaniline herbicide resistance and the microtubule cytoskeleton. Trends Plant Sci. 1999:4:112-6.

42. Ashton FM, Crafts AS. Dinitroanilines. In: Ashton FM, Crafts AS, eds. Mode of action of herbicides. New York: John Wiley \& Sons; 1981. pp. 201-23.

43. Cleary AL, Hardham AR. Depolymerization of microtubule arrays in root tip cells by oryzalin and their recovery with modified nucleation patterns. Can J Bot. 1988;66:2353-66.

44. Olson KR, Mclntosh JR, Olmsted JB. Analysis of MAP4 function in living cells using green fluorescent protein (GFP) chimeras. J Cell Biol. 1995;130:639-50.

45. Dostál V, Libusová L. Microtubule drugs: action, selectivity, and resistance across the kingdoms of life. Protoplasma. 2014;251:991-1005.

46. Jordan MA, Wilson L. Microtubules as a target for anticancer drugs. Nat Rev Cancer. 2004:4:253-65.

47. Gunning BES, Hardham AR. Microtubules. Annu Rev Plant Physiol. 1982;33:651-98.

48. Bringmann M, Landrein B, Schudoma C, Hamant O, Hauser M, Persson S. Cracking the elusive alignment hypothesis: the microtubule - cellulose synthase nexus unraveled. Trends Plant Sci. 2012;17:666-74.

49. Brabham C, DeBolt S. Chemical genetics to examine cellulose biosynthesis. Front Plant Sci. 2013:3:309.

50. Sabba RP, Vaughn KC. Herbicides that inhibit cellulose biosynthesis. Weed Sci. 1999:14:757-63.

51. Nodet P, Capellano A, Fevre M. Morphogenetic effects of Congo red on hyphal growth and cell wall development of the fungus Saprolegnia monoica. J Gen Microbiol. 1990;136:303-10.

52. Humphrey TV, Bonetta DT, Goring DR. Sentinels at the wall: cell wall receptors and sensors. New Phytol. 2007;176:7-21.

53. Ringli C. Monitoring the outside: cell wall-sensing mechanisms. Plant Physiol. 2010;153:1445-52.

54. Hématy K, Sado P, Van Tuinen A, Rochange S, Desnos T, Balzergue S, et al. A receptor-like kinase mediates the response of Arabidopsis cells to the inhibition of cellulose synthesis. Curr Biol. 2007;17:922-31.

55. Duan Q, Kita D, Li C, Cheung AY, Wu H-M. FERONIA receptor-like kinase regulates $\mathrm{RHO}$ GTPase signaling of root hair development. Proc Natl Acad Sci USA. 2010;107:17821-6.

56. Marga F, Grandbois M, Cosgrove DJ, Baskin TI. Cell wall extension results in the coordinate separation of parallel microfibrils: evidence from scanning electron microscopy and atomic force microscopy. Plant J. 2005;43:181-90.

57. Hamada T. Microtubule organization and microtubule-associated proteins in plant cells. Int Rev Cell Mol Biol. 2014;312:1-52.

\section{Publisher's Note}

Springer Nature remains neutral with regard to jurisdictional claims in published maps and institutional affiliations. 